\title{
INFLUENCE OF THE COMPRESSIVE STRENGTH (FCK) IN THE ANALYSIS OF CONCRETE STRUCTURES DEFORMATION
}

\author{
Bruno Leonardo Pontes Cabral ${ }^{1}$, Wagner Queiroz Silva ${ }^{2}$
}

\footnotetext{
${ }^{1}$ Graduando em Engenharia Civil pelo Centro Universitário do Norte (UNINORTE), Brasil, Rua Huascar de Figueiredo, 290, Centro, Manaus/AM.

${ }^{2}$ Prof. Doutor do Departamento de Engenharia Civil da Universidade Federal do Amazonas (FT/UFAM), Av. Rodrigo Otávio n 6200 Campus universitário, Coroado, Manaus/AM
}

Email: brunocabra199@gmail.com, wqs@ufam.edu.br

Received: April 02 ${ }^{\text {th }}, 2019$

Accepted: April 25th 2019

Published: June $30^{\text {th }}, 2019$

Copyright (02016 by authors and Institute of Technology Galileo of Amazon (ITEGAM). This work is licensed under the Creative Commons Attribution International License (CC BY 4.0). https://creativecommons.org/lice nses/by/4.0/

\section{ABSTRACT}

The Compressive strength (fck) has become the reference parameter in design of Reinforced Concrete Structures due to the ease of testing and the possibility of deducing other material properties from this one. The present paper seeks to analyze how the fck value influences the analysis of deformations of reinforced concrete structures. This verification will be done from the modeling of a hypothetical 10floors building for the fck values of $30 \mathrm{MPa}, 35 \mathrm{MPa}, 40 \mathrm{MPa}$ and $60 \mathrm{MPa}$. From the floor plan, the cross-section of the structural elements was pre-dimensioned; a plan of actions and loads according to ABNT norms was elaborated, and the modeling was carried out using the software SAP2000. Seven models of the same building were obtained, in which the influence of the fck in several parameters was evaluated, such as: the geometry of the pieces; the shortening of the pillars; the vertical displacement of beams and slabs and the horizontal displacements of the building. It was found that the modification of the compressive strength of the concrete contributed significantly to the determination of material properties and section geometry. The influences in the vertical and horizontal displacements were also observed, besides the final load of the pillars. It was concluded that the influence of fck value on structural analysis verifications occurs predominantly through the change in the final stiffness of the structural elements.

Keywords: compressive strength (fck); pre-dimensioning; Modulus of Elasticity; deformation.

\section{INFLUÊNCIA DA RESISTÊNCIA CARACTERÍSTICA À COMPRESSÃO DO CONCRETO (FCK) NA ANÁLISE DE DEFORMAÇÃO DA ESTRUTURA}

\section{RESUMO}

A resistência à compressão (fck) se tornou parâmetro de referência nos projetos de estruturas de concreto devido à facilidade de realização de ensaio e à possibilidade de deduzir outras propriedades a partir desta. O presente trabalho busca analisar como o valor de fck influencia a análise de deformações de estruturas de concreto armado. Esta verificação será feita a partir da modelagem de um edifício hipotético de 10 andares para os valores de fck de $30 \mathrm{MPa}, 35 \mathrm{MPa}, 40 \mathrm{MPa}$ e $60 \mathrm{MPa}$. A partir da planta baixa, procedeu-se com o pré-dimensionamento da seção transversal dos elementos estruturais; foi elaborado um plano de ações e carregamentos conforme normas técnicas da ABNT, e a modelagem foi realizada utilizando o programa computacional SAP2000. Obtiveram-se sete modelos do mesmo edifício, nos quais foi avaliada a influência do fck em diversos parâmetros como: a geometria das peças; o encurtamento dos pilares; o deslocamento vertical de vigas e lajes e os deslocamentos horizontais do edifício. Constatou-se que a modificação da resistência característica à compressão do concreto contribuiu significativamente na determinação de propriedades dos materiais e da geometria das seções. Também se observaram influências nos deslocamentos verticais e horizontais, além da carga final dos pilares. Concluiu-se que a influência do valor de fck nas verificações de análise estrutural se dá predominantemente através da mudança na rigidez final das peças estruturais.

Palavras-Chave: Resistência Característica à compressão (fck), pré-dimensionamento, módulo de elasticidade, deformações. 


\section{INTRODUÇÃO}

$\mathrm{O}$ concreto, produzido à taxa de quase uma tonelada por ser humano, é o segundo material mais consumido do mundo, perdendo apenas para água [1]. Esse uso em larga escala é justificado pelas vantagens do concreto em relação a outros materiais estruturais; entre as principais vantagens destacam-se: flexibilidade de formas; baixo custo de matéria-prima, mão de obra e manutenção; processos construtivos consagrados; baixa permeabilidade; boa resistência ao fogo, a choques e vibrações; durabilidade, entre outras [2].

O concreto é um compósito, isto é, uma mistura de cimento, agregado miúdo e graúdo e água, com possibilidade de usar aditivos para melhorar algumas de suas características. Esses materiais, bem como a proporção em que se apresentam no traço e procedimentos de preparo, definem a qualidade e as propriedades do concreto endurecido. Inúmeras são as propriedades do concreto de interesse para o projeto - porosidade, impermeabilidade, elasticidade, contração térmica, entre outros -, contudo a resistência à compressão se tornou parâmetro de referência nos projetos de estruturas de concreto devido à facilidade de realização de ensaio e à possibilidade de deduzir outras propriedades [1] .

A classe de resistência do concreto é identificada pela sua resistência característica à compressão (fck) medida por ensaio mecânico aos 28 dias de cura. Em função da resistência à compressão, a NBR 8953:2015 [3] divide o concreto estrutural em classes de resistência, que são subdividas em grupo I, classe C20 a C50, e grupo II, de C55 a C100 - também chamado concreto de alta resistência. A resistência mínima à compressão adotada em projeto é determinada pela NBR 6118:2014 [4] para cada estrutura de acordo com a classe de agressividade ambiental.

Um exemplo da importância da resistência à compressão é o trabalho de Bernardo e Vargas [5], que analisou qual concreto da classe I apresenta melhores resultados técnicos e econômicos no projeto de um edifício residencial de 17 pavimentos, chegando à conclusão que os concretos de $30 \mathrm{MPa}$ e $35 \mathrm{MPa}$ apresentam menores custos. Para entender a razão desse resultado, é importante destacar que, à medida que influencia a qualidade do concreto, a resistência à compressão influi diretamente nas características geométricas dos elementos estruturais - como as medidas da seção transversal (determinante no consumo de material) - e também está presente em diversas formulações de esforços e prédimensionamento, interferindo consequentemente em todo o projeto estrutural.

O projeto estrutural de um edifício pode ser dividido basicamente em concepção, análise e dimensionamento. A concepção abrange a elaboração do projeto arquitetônico, consoante a função do edifício, e definição dos materiais estruturais a serem utilizados na obra. Na fase de análise, por sua vez, buscase prever o comportamento da estrutura calculando esforços (reações de apoio, tensões solicitante e resistente) e deformações (deslocamento e rotações) para diferentes estágios de carga [6] parâmetros obtidos a partir da concepção estrutural. Conhecendo o comportamento da estrutura, pode-se então dimensioná-la e emitir as pranchas e documentos especificando detalhes essenciais para obter uma estrutura segura e econômica. Todavia, Benincá [7] destaca que existem atualmente muitos softwares que realizam a análise e o dimensionamento da estrutura de forma integrada; essa integração tem gerado em alguns profissionais o mau hábito de não interpretar criticamente o resultado da análise da estrutural, deixando de lado o entendimento dos resultados.

Assim, diante da relevância da resistência característica à compressão do concreto no projeto de estruturas de concreto armado e da recente cultura de menosprezar os resultados da análise estrutural, o presente trabalho visa destacar a importância desta etapa de projeto, buscando explicitar a influência do valor da resistência à compressão (fck) na análise de deformações da estrutura.

\section{FUNDAMENTAÇÃO TEÓRICA}

\section{II.1 MODELO E ANÁLISE ESTRUTURAL}

Para [6] descreve quatro níveis de modelos de análise de estruturas. O Modelo Real, que é como a estrutura é construída; o Modelo Estrutural ou Matemático, no qual o comportamento da estrutura é idealizado com base nas equações de equilíbrio, relações de compatibilidade e leis constitutivas dos materiais. Com isso, os elementos estruturais são representados por conjunto de linhas, cujas informações tridimensionais são representadas pelas propriedades globais de suas seções transversais. A composição pode ser feita por modelos bidimensionais, de maior simplicidade, ou tridimensionais, considerando a solidariedade entre os elementos. Tem-se também o Modelo Discreto, que é uma discretização do modelo estrutural, na qual variáveis hiperestáticas são adotadas, obtendo soluções básicas que serão submetidas à superposição. E por fim, o Modelo Computacional, que utiliza de métodos iterativos, baseados em elementos finitos e método da rigidez direta.

\section{2 RELAÇÃO DE PROPRIEDADES COM A RESISTÊNCIA À COMPRESSÃO}

De acordo com a NBR 6118:2014 [4], na falta de ensaios específicos, os valores de resistência do concreto à tração direta $\left(f_{c t}\right.$ em seu limite inferior e superior) podem ser determinados a partir do fck pelas equações (1) e (2):

$$
f_{c t k, \text { inf }}=0,7 . f_{c t, m}
$$

Onde:

$f_{c t k, \text { inf }}=$ resistência característica à tração limite inferior;

$f_{c t, m}=$ resistência à tração direta.

$$
f_{c t k, \text { sup }}=1,3 \cdot f_{c t, m}
$$

Onde:

$f_{c t k, \text { sup }}=$ resistência característica à tração limite superior;

- para concreto do grupo I:

$$
f_{c t, m}=0,3 \cdot f_{c k}^{2 / 3}
$$

- para concreto do grupo II, até $90 \mathrm{Mpa}$ :

$$
f_{c t, m}=2,2 \cdot \ln \left(1+0,11 \cdot f_{c k}\right)
$$

Para o módulo de elasticidade ou módulo de deformação tangente inicial $\left(\mathrm{E}_{\mathrm{ci}}\right)$, na falta de ensaio, a mesma NBR 6118:2014 prescreve as equações (5) e (6):

- para concreto do grupo I:

$$
E_{c i}=\alpha_{E} \cdot 5600 \cdot \sqrt{f_{c k}}
$$


- para concreto do grupo II:

$$
E_{c i}=21,5.10^{3} \cdot \alpha_{E} \cdot\left(\frac{f_{c k}}{10}-1,25\right)^{1 / 3}
$$

Sendo, $\alpha_{\mathrm{E}}$ coeficiente em função do agregado graúdo:

$\alpha_{\mathrm{E}}=1,2$ para basalto e diobásio;

$\alpha_{\mathrm{E}}=1,0$ para granito e gnaisse;

$\alpha_{\mathrm{E}}=0,9$ para calcário;

$\alpha_{\mathrm{E}}=0,7$ para o arenito

Já para o módulo de deformação secante $\left(\mathrm{E}_{\mathrm{cs}}\right)$, tem-se a equação (7):

$$
E_{c s}=\alpha_{i} \cdot E_{c i}
$$

Sendo

$$
\alpha_{i}=0,8+0,2 \cdot \frac{f_{c k}}{80} \leq 1,0
$$

Percebe-se que a elasticidade do concreto está diretamente relacionada com o valor do fck, o que implica no seu desempenho mecânico (nível de deformações) frente às solicitações de esforços que a estrutura estará submetida.

\section{II.3 PRÉ-DIMENSIONAMENTO DE ESTRUTURAS DE CONCRETO}

Estruturas de concreto armado podem ser prédimensionadas pela Equação 9 para lajes; Equação 10 para vigas e Equação 11 para pilares [2]:

$$
h=(2,5-0,1 . n) .0,01+c+\frac{\phi}{2}
$$

Onde:

$\mathrm{h}=$ espessura

$\mathrm{n}=$ número de bordas engastadas

$1 \leq\{1 \mathrm{x}$ ou $0,7 \mathrm{ly}$, sendo ly o maior vão

$\mathrm{c}=$ cobrimento

$\phi=$ diâmetro da barra

$$
h=\frac{L}{10}
$$

Sendo:

$\mathrm{h}=$ espessura

$\mathrm{L}=$ vão teórico

$$
A_{c}=\frac{30 \cdot \alpha \cdot A_{x} \cdot(n+0,7)}{f_{c k}+0,01 \cdot\left(69,2-f_{c k}\right)}
$$

$\alpha=$ coeficiente de excentricidade

$\mathrm{A}_{\mathrm{c}}=$ área da seção do pilar

$\mathrm{A}_{\mathrm{x}}=$ área de influência

$\mathrm{n}=$ número de pavimentos tipo

A partir das Equações 9 a 11, percebe-se que o prédimensionamento de laje e viga não depende das propriedades dos materiais, ainda que na fase de dimensionamento a posição da linha neutra seja determinante para o funcionamento desses elementos.

Já o pilar tem área da seção inversamente proporcional à resistência do concreto; com isso, quanto maior o fck, menor será a área da seção transversal e, portanto, menor será o consumo do concreto. Todavia, a redução da seção do pilar, implica elevada esbeltez que deve ser analisada criticamente devido à suscetibilidade a deslocamentos laterais e ao efeito da flambagem, como será abordado adiante.

\section{II.4 ESFORÇOS E DESLOCAMENTOS}

Os esforços, objeto de estudo da análise de estruturas, em nada dependem das propriedades dos materiais - por tanto, são independentes do fck - como pode ser visto nas equações fundamentais da mecânica das estruturas, Equações (12) e (13), obtidas de SUSSEKIND [8]:

$$
\begin{array}{r}
V=\frac{d M}{d x} \\
-w=\frac{d V}{d x}
\end{array}
$$

Já o cálculo das deformações - deslocamentos ou rotações -, também estudadas na análise de estruturas, dependem do momento de inércia e do módulo de elasticidade (este diretamente dependente do fck como visto anteriormente), como se pode observar a partir de equações obtidas da resistência dos materiais. As vigas, elementos horizontais em que a flexão é preponderante, as deflexões podem ser calculadas pela equação diferencial (14), a partir do qual se obtém a linha elástica (diagrama da deflexão do eixo longitudinal que passa pelo centroide da seção transversal) [9].

$$
E I \frac{d^{4} v}{d^{4} x}=-w(x)
$$

Onde:

$\mathrm{E}=$ módulo de elasticidade;

I = momento de inércia;

$v=$ deflexão (ou deslocamento) do ponto;

$x=$ posição ao longo do elemento;

$w=$ carga.

Já os pilares, nos quais as cargas axiais de compressão são predominantes, estão sujeitos a um encurtamento longitudinal, regido pela equação (15) [9]:

$$
\delta=\sum \frac{N \cdot L}{E \cdot A}
$$

Sendo:

$\mathrm{N}=$ carga axial;

$\mathrm{E}=$ módulo de elasticidade;

$\mathrm{L}=$ comprimento do elemento estrutural;

A = área da seção;

\section{II.5 FLAMBAGEM E ESBELTEZ}

Além do encurtamento dos pilares, outra consequência de cargas normais de compressão é a flambagem. Definida por Martha [6] como perda de estabilidade, a flambagem é uma oscilação lateral do pilar no sentido de menor inércia quando submetido a uma carga crítica (Equação 16). A Carga crítica, conforme destacado por Hibbeler (2010), não depende diretamente da resistência do material constituinte, mas de sua rigidez e da geometria da peça (comprimento e momento de inércia), além das vinculações em suas extremidades. 


$$
P_{c r}=\frac{\pi^{2} \cdot E \cdot I}{(K \cdot L)^{2}}
$$

Onde,

$\mathrm{E}=$ Módulo de Elasticidade;

$\mathrm{I}=$ Momento de inércia;

$\mathrm{K}$ = Fator de comprimento efetivo;

$\mathrm{L}=$ comprimento longitudinal do pilar.

A tendência de flambagem de um pilar pode ser mensurada pelo índice de esbeltez, razão entre o comprimento efetivo do pilar (le) e o raio de giração da peça (i). (Equação 17) [2]. Estes são calculados em função da área e do momento de inércia, variáveis diretamente relacionadas ao fck, conforme visto no pré-dimensionamento.

$$
\lambda=\frac{l e}{i}
$$

Onde,

$$
i=\sqrt{\frac{I}{A}}
$$

Sendo,

$\mathrm{I}=$ Momento de inércia;

$\mathrm{A}=$ área da seção.

Durante o dimensionamento, os pilares podem ser classificados, quanto ao Índice de esbeltez, em:

- $\quad$ pilares robustos, curtos ou pouco esbeltos $\rightarrow \lambda \leq \lambda 1$

- $\quad$ pilares medianamente esbeltos $\rightarrow \lambda 1<\lambda \leq 90$

- $\quad$ pilares esbeltos $\rightarrow 90<\lambda \leq 140$

- pilares excessivamente esbeltos $\rightarrow 140<\lambda \leq 200$

Sendo $\lambda 1$ definido como esbeltez limite, valor a partir do qual os efeitos locais de segunda ordem devem ser considerados [2].

\section{METODOLOGIA}

O presente trabalho compreende a análise de desempenho e modelagem de estruturas, com abordagem bibliográfica quanto às informações técnicas adotadas e normativas quanto à obtenção dos dados materiais de análise que foram descritos, e submetidos a uma análise quantitativa.

A verificação da influência do fck na análise de estruturas de concretos neste trabalho foi realizada a partir da modelagem para os valores de fck de $30 \mathrm{MPa}, 35 \mathrm{MPa}, 40 \mathrm{MPa}$ e $60 \mathrm{MPa}$, de um edifício hipotético de 10 andares, com 8 salas de aula e banheiro masculino e feminino por pavimento, conforme planta baixa da Figura 1 a seguir.

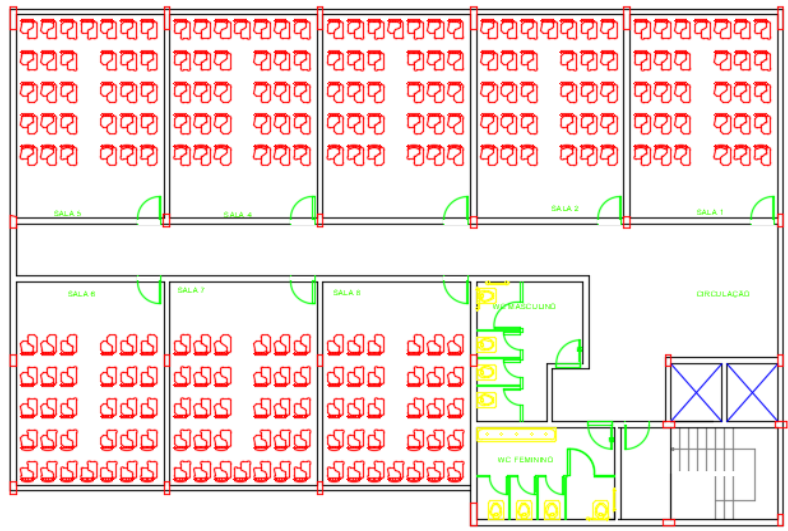

Figura1: Planta Baixa do Pavimento Tipo. Fonte: Autores, (2019).

A partir da planta baixa, procedeu-se com o prédimensionamento da seção transversal dos elementos estruturais segundo as equações 9 a 11. Neste pré-dimensionamento obtiveram-se diferentes medidas para cada pilar, que foram restringidas a 5 padrões de medidas, que não levassem a mudança maiores que $20 \%$ da área calculada. Esses ajustes, em um projeto real, facilitariam a execução das fôrmas no canteiro de obras chegando-se à planta de Fôrma da Figura 2, que traz as medidas dos pilares para os diferentes valores de fck.

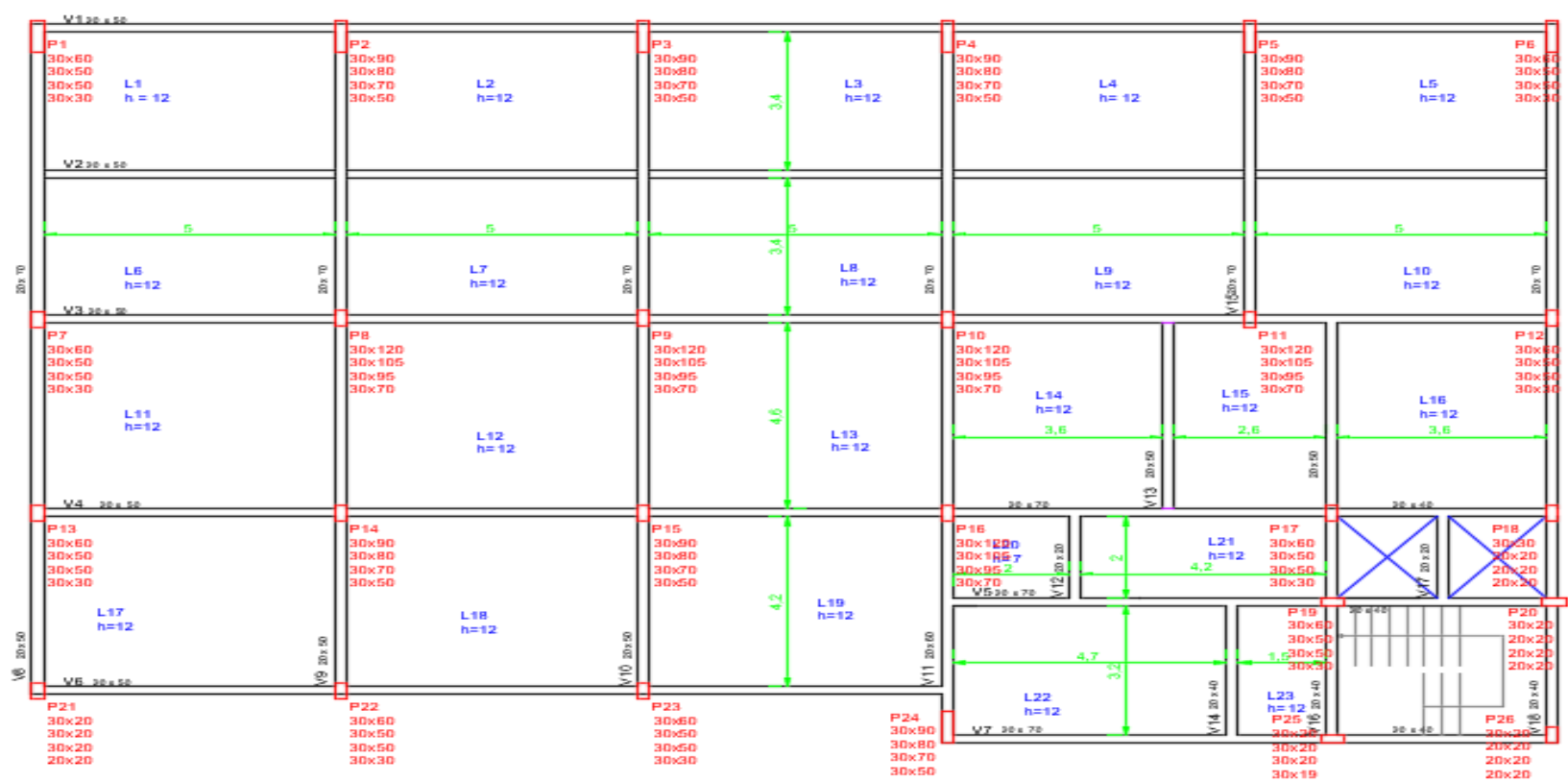

Figura 2: Planta de Fôrma.

Fonte: Autores, (2019). 
Em seguida, estabeleceu-se o plano de carregamento da estrutura a partir das prescrições da NBR 6120:1980 [10]. No plano de carregamento, define-se que:

- O peso próprio das peças estruturais foi definido no SAP2000 para concreto de peso específico igual a 25 $\mathrm{kN} / \mathrm{m}^{3}$;

- Cargas permanentes da alvenaria: $4 \mathrm{kN} / \mathrm{m}$, considerando bloco cerâmico e reboco em cada face com altura de 2,8m;

- Cargas variáveis devido ao uso comercial: $3 \mathrm{kN} / \mathrm{m}^{2}$;

- Carga da escada: $11 \mathrm{kN} / \mathrm{m}$, aplicada sobre a viga V16, entre os pilares P19 e P25.

Os esforços devido ao vento foram calculados segundo a NBR 6123:1988 [11], considerando vento básico de Manaus, $25 \mathrm{~m} / \mathrm{s}$; terreno plano; edifício com alto fator de ocupação; nas cotas de $3 \mathrm{~m}, 6 \mathrm{~m}, 12 \mathrm{~m}, 18 \mathrm{~m}, 24 \mathrm{~m}$ e $33 \mathrm{~m}$; para ventos a $180^{\circ}$ e $270^{\circ}$ (maiores dimensões) aplicados pontualmente na extremidade das vigas paralelas à direção do vento considerada.

Outro item do plano de carregamento, definiram-se as combinações de carga segundo a NBR 6118:2014 [4]:

- Combinação Última Normal sem vento para verificar carga dos pilares;

- Combinação Frequente de Serviço com vento a $180^{\circ}$ para verificar deslocamentos no Eixo X, análise P-Delta;

- Combinação Frequente de Serviço com vento a $270^{\circ}$ para verificar deslocamentos no Eixo Y, análise P-Delta;

- Combinação Frequente de Serviço com vento a $270^{\circ}$ para verificar deslocamentos no Eixo Z;

Definido o plano de carga, fez-se a modelagem do edifício no software SAP2000, que permite a simulação da estrutura em um modelo tridimensional, além de outros recursos que possibilita a verificação do edifício considerando a solidariedade dos elementos estruturais e as possíveis redistribuições de esforços entre vigas e pilares. A escolha do SAP2000 como software para este estudo também se deu pela facilidade de uso e pelos recursos disponíveis para esse tipo de análise.

O primeiro modelo foi feito para o concreto com classe de resistência C30, que serviu de base para os demais modelos. A partir do modelo com fck $=30 \mathrm{Mpa}$, geraram-se os demais modelos, redefinindo o material (resistência à compressão e o módulo de elasticidade do concreto) e adotando o seguinte critério para área das seções dos pilares:

- Considerando a mudança da área conforme fck adotado, modelo mais próximo da realidade;

- Desconsiderando a mudança dessa área, isto é, mantevese a área calculada para os pilares do C30 nos demais modelos, alterando apenas o material para C35, C40 e C60. Com isso, busca-se verificar a influência apenas do fck na deformação.

Desta forma, obtiveram-se sete modelos do mesmo edifício, nos quais foi avaliada a influência do fck na geometria das peças; no encurtamento dos pilares; no deslocamento vertical de vigas e lajes; além do deslocamento horizontal do edifício nos eixos X e Y. As deformações foram organizadas e comparadas segundo a classe de resistência do concreto e da área considerada do pilar.

\section{RESULTADOS E DISCUSSÕES}

\section{IV.1 INFLUÊNCIA DO FCK NA GEOMETRIA DAS PEÇAS}

Aplicando as equações 9 a 11 para o pré-dimensionamento dos pilares do prédio analisado e aplicando os ajustes de padronização, chegou-se às áreas adotadas expressas na Tabela 1 a seguir.

Tabela 1 Variação da área e carga dos pilares segundo o fck.

\begin{tabular}{|c|c|c|c|c|c|c|c|c|}
\hline $\begin{array}{l}\mathrm{Eck} \\
(\mathrm{mPa})\end{array}$ & & & & 35 & & & & 60 \\
\hline PILAR & $\begin{array}{l}\text { AREA } \\
\left(\mathrm{cm}^{2}\right)\end{array}$ & $\begin{array}{l}\text { CARGA } \\
(\mathrm{aN})\end{array}$ & $\begin{array}{l}\text { AREA } \\
\left(\mathrm{cm}^{2}\right)\end{array}$ & & $\begin{array}{l}\text { AREA } \\
\left(\mathrm{cm}^{2}\right)\end{array}$ & & $\begin{array}{l}\text { AREA } \\
\left(\mathrm{cm}^{2}\right)\end{array}$ & $\begin{array}{l}\text { CARGA } \\
(\mathrm{GN})\end{array}$ \\
\hline P1 & 1800 & 3958,9 & 1500 & 3828,3 & 1500 & 3909,9 & 900 & 3539,1 \\
\hline $\mathrm{P} 2$ & 2700 & 7707,9 & 2400 & 7644,6 & 2100 & 7480,8 & 1500 & 7280 \\
\hline P3 & 2700 & 7053,3 & 2400 & 6982,7 & 2100 & 6923,4 & 1500 & 6730,8 \\
\hline P4 & 2700 & 7517,2 & 2400 & 7421,3 & 2100 & 7330,7 & 1500 & 7066 \\
\hline P5 & 2700 & 7600,4 & 2400 & 7542,7 & 2100 & 7374,2 & 1500 & 7250,7 \\
\hline P6 & 1800 & 3990 & 1500 & 3847 & 1500 & 3912 & 900 & 3571,9 \\
\hline P7 & 1800 & 5819,34 & 1500 & 5705,9 & 1500 & 5793,4 & 900 & 5454,6 \\
\hline PS & 3600 & 12220,6 & 3150 & 12179,4 & 2850 & 12086,3 & 2100 & 12450 , \\
\hline P9 & 3600 & 11567,2 & 3150 & 11458,5 & 2850 & 11456,5 & 2100 & 11481 , \\
\hline P10 & 3600 & 12011 & 3150 & 11899,4 & 2850 & 11869,2 & 2100 & 11897,9 \\
\hline P11 & 3600 & 11842,3 & 3150 & 11880,5 & 2850 & 11725,4 & 2100 & 12179,5 \\
\hline P12 & 1800 & 5826,1 & 1500 & 5834,6 & 1500 & 5900,5 & 900 & 542 \\
\hline P13 & 1800 & 4790,8 & 1500 & 4852,7 & 1500 & 4920 & 900 & 4679, \\
\hline P14 & 2700 & 8806 & 2400 & 8895,9 & 2100 & 8605 & 1500 & 8823, \\
\hline P15 & 2700 & 8565 & 2400 & 8558,5 & 2100 & 8335,8 & 1500 & 8361, \\
\hline P16 & 3600 & 11355,35 & 3150 & 11306,7 & 2850 & 11186,3 & 2100 & 1140 \\
\hline P17 & 1800 & 6158,4 & 1500 & 6057,8 & 1500 & 6151,9 & 900 & 5554,4 \\
\hline P18 & 600 & 1554,54 & 400 & 1369,9 & 400 & 1375,8 & 400 & 164 \\
\hline P19 & 1800 & 5669,4 & 1500 & 5480,1 & 1500 & 5610,7 & 900 & 4793,1 \\
\hline $\mathrm{P} 20$ & 600 & 1085,5 & 400 & 923,2 & 400 & 950,3 & 400 & 1059,8 \\
\hline P21 & 1050 & 2387 & 600 & 1924,65 & 600 & 1924,6 & 400 & 1829,9 \\
\hline P22 & 1800 & 4873,5 & 1500 & 4915,8 & 1500 & 5004,54 & 900 & 4559, \\
\hline P23 & 1800 & 4847,2 & 1500 & 4708,4 & 1500 & 4837,2 & 900 & 4346 \\
\hline P24 & 2700 & 6410,6 & 2400 & 6438,5 & 2100 & 6206,2 & 1500 & 6079,3 \\
\hline P25 & 600 & 2213 & 600 & 2298,2 & 600 & 2399 & 570 & 2638,2 \\
\hline P26 & 600 & 827,2 & 400 & 877,7 & 400 & 685,3 & 400 & 712. \\
\hline
\end{tabular}

Fonte: Autores, (2019).

Observa-se que apenas o aumento do fck provocou uma redução da área da seção transversal dos pilares em relação ao concreto C30 na ordem de $16,7 \%$ para os pilares com C35; de $21,3 \%$ para os pilares com C40; e de $43,7 \%$ para os pilares com C60. Ressalta-se que devido a padronização aplicada, muitos dos pilares ficaram com medidas semelhantes àqueles de fck $=35 \mathrm{MPa}$.

Na Tabela 1 acima, também pôde-se verificar uma ligeira redução da carga nos pilares, que se deve à redução do consumo de concreto, devido à diminuição da seção. Para o C35, houve redução média de 70,2 kN em relação à carga com o C30; já para o C40, a redução média foi de $104 \mathrm{kN}$; e para o C60, a redução média foi de $224,6 \mathrm{kN}$.

Todavia, verificou-se ainda, ao contrário do esperado, um aumento de carga em alguns pilares (marcados em rosa) em relação à sua carga com concreto $\mathrm{C} 30$. Esses pequenos acréscimos de carga podem ter acontecido em função de uma redistribuição das cargas no sistema hiperestático, visto que os pilares tiveram o momento de inércia e módulo de elasticidade modificados, alterando assim sua rigidez.

Vale, por fim, destacar que quando as áreas dos pilares para o concreto C30 foi mantida para C35, C40 e C60, não houve alteração das cargas entre os modelos. Este resultado indica que a influência do fck na distribuição dos esforços na estrutura é pouco significativa, porém observam-se redistribuições causadas pela 
mudança das propriedades geométricas da seção, pois nesse caso houve influência da rigidez das peças.

\section{IV.2 ENCURTAMENTO DOS PILARES}

A análise do encurtamento dos pilares foi feita para combinando os seguintes critérios:

a) Quanto a área da seção transversal do pilar:

- Considerando a mudança da área conforme fck adotado, modelo mais próximo da realidade;

- Desconsiderando a mudança dessa área, isto é, mantevese a área calculada para os pilares do C30 nos demais modelos, alterando apenas o material para C35, C40 e C60. Com isso, busca-se verificar a influência do fck apenas na deformação.

b) Quanto ao trecho considerado do pilar:

- Análise do primeiro lance do pilar (do térreo ao primeiro pavimento, $\mathrm{L}_{\text {pilar }}=3,00 \mathrm{~m}$ ), situação em que as ações verticais são mais significativas em detrimento a ação do vento;

- Análise no topo do edifício $\left(\mathrm{L}_{\text {pilar }}=33,00 \mathrm{~m}\right)$, situação em que a ação do vento é tão significativa quanto às cargas verticais.

Aplicando os referidos critérios ao pilar P8, que apresenta maior carga atuante, chegou-se aos seguintes resultados:

Tabela 2: Encurtamento do Pilar P8.

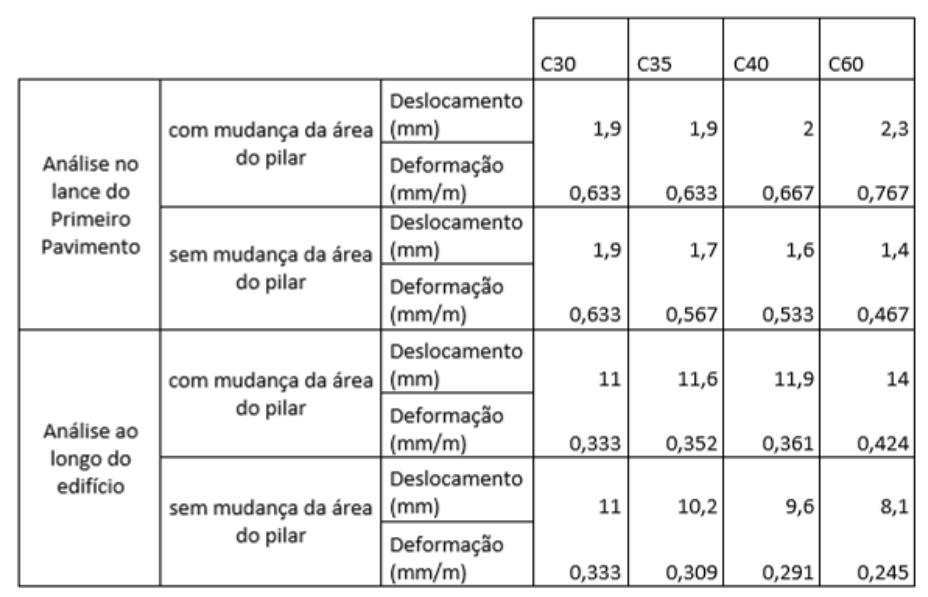

Fonte: Autores, (2019).

Analisando os modelos feitos com a mesma área da seção transversal, obteve-se um encurtamento menor dos pilares à medida que se adotava um fck maior. Esse resultado se deve a influência do fck na determinação do Módulo de Elasticidade (diretamente proporcional à resistência característica à compressão) e apenas confirma a Lei de Hooke, presente neste trabalho através da Equação 15. Segundo a Lei de Hooke, para uma mesma tensão (já que a carga e área dos pilares foram igualadas nos diferentes modelos), quanto maior o Módulo de elasticidade, menor será a deformação.

Por outro lado, quando se analisaram os modelos que consideram a modificação das áreas conforme o fck, as deformações se apresentaram de maneira completamente oposta à situação anterior, crescendo ao passo que se adotava um fck maior. Essa mudança no comportamento das deformações pode ser atribuída ao aumento da esbeltez com a diminuição da área da seção transversal, que deixa a estrutura suscetível à redistribuição dos esforços conforme verificado anteriormente.

Já a análise quanto ao trecho considerado do pilar não demonstrou ser um critério determinante para descrever a influência do fck na análise do encurtamento, apenas confirmou o comportamento descrito anteriormente.

\section{IV.3 DESLOCAMENTOS VERTICAIS EM LAJES}

Verificaram-se as flechas (deslocamentos verticais) geradas nas lajes considerando as alterações na área da seção transversal do pilar e considerando a mesma área para os pilares nos diferentes modelos. Para exemplificar a formação das flechas tomaram-se as lajes L11 e L14, que têm os deslocamentos verticais descritos na Tabela 3 a seguir.

Tabela 3: Deslocamentos verticais em lajes.

\begin{tabular}{|c|c|c|c|c|c|c|c|c|}
\hline \multirow{4}{*}{$\begin{array}{c}\text { CLASSE DE } \\
\text { RESISTÊNCIA } \\
\text { DO } \\
\text { CONCRETO }\end{array}$} & \multicolumn{4}{|c|}{ Laje 11 (ponto 5,5) } & \multicolumn{4}{|c|}{ Laje 14 (ponto 6,5) } \\
\hline & \multicolumn{4}{|c|}{ Deslocamento vertical $(\mathrm{mm})$} & \multicolumn{4}{|c|}{ Deslocamento vertical $(\mathrm{mm})$} \\
\hline & \multicolumn{2}{|c|}{$\begin{array}{l}\text { com mudança da } \\
\text { área do pilar }\end{array}$} & \multicolumn{2}{|c|}{$\begin{array}{c}\text { sem mudança da } \\
\text { área do pilar }\end{array}$} & \multicolumn{2}{|c|}{$\begin{array}{c}\text { com mudança da } \\
\text { área do pilar }\end{array}$} & \multicolumn{2}{|c|}{\begin{tabular}{|c|} 
sem mudança da \\
área do pilar
\end{tabular}} \\
\hline & Absoluta & Relativa & Absoluta & Relativa & Absoluta & Relativa & Absoluta & Relativa \\
\hline C30 & 6,5 & 0 & 6,5 & 0 & 6,2 & 0 & 6,2 & 0 \\
\hline C35 & 6,3 & 0,2 & 6 & 0,5 & 6 & 0,2 & 5,7 & 0,5 \\
\hline $\mathrm{C} 40$ & 6 & 0,5 & 5,6 & 0,9 & 5,7 & 0,5 & 5,2 & 1 \\
\hline $\mathrm{C} 60$ & 6 & 0,5 & 4,8 & 1,7 & 5,5 & 0,7 & 4,6 & 1,6 \\
\hline
\end{tabular}

Fonte: Autores, (2019).

Analisando a Tabela 3, percebe-se que as deformações se apresentaram dentro do esperado, isto é, em valores decrescentes conforme se aumentava o fck, atendo assim à Lei de Hooke. Quanto à diferença dos deslocamentos para a consideração ou não da mudança da área da seção transversal do pilar, deduz-se que a redistribuição dos esforços contribui para aumentar as flechas em lajes.

\section{IV.4 DESLOCAMENTOS VERTICAIS EM VIGAS}

Para exemplificar o comportamento das vigas quanto à formação de flechas, escolheram-se as vigas V2 e V10 por

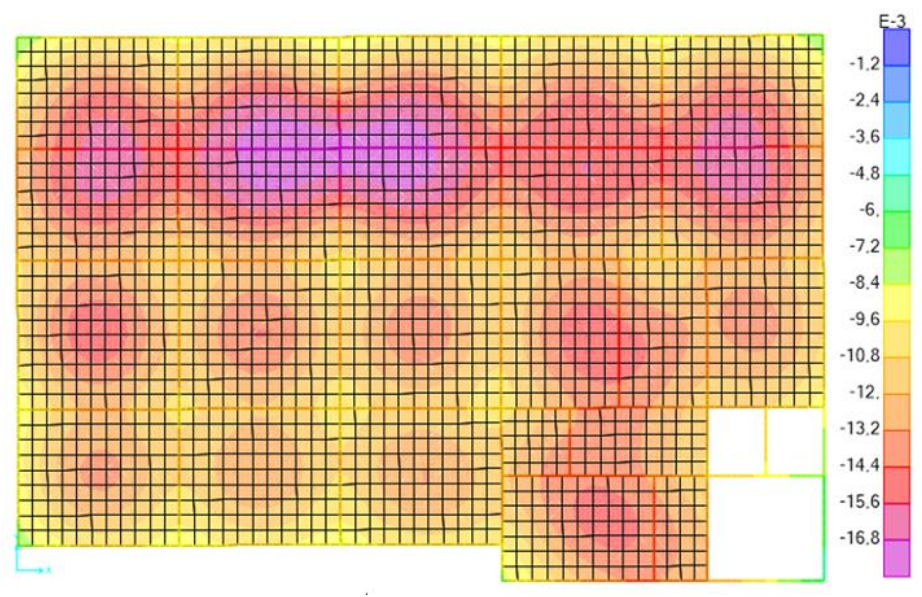

Figura 3: Mapa de deslocamentos verticais em $\mathrm{Z}=33 \mathrm{~m}$.

Fonte: Autores, adaptado de SAP2000, (2019).

apresentarem as maiores deformações verticais, como se pode verificar na Figura 3. E destas obtiveram-se os deslocamentos no meio do vão entre as lajes L2 e L7 (S1), no ponto onde V2 se apoia em V10 (S2) e meio do vão entre as lajes L12 e L13 (S3). 


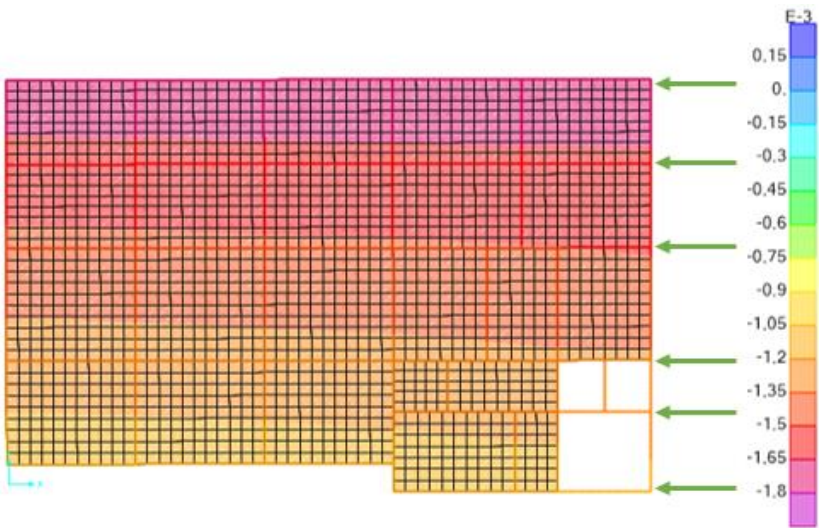

Figura 4: Deslocamento em X.

Fonte: Autores, adaptado de SAP2000, (2019).

Esses deslocamentos estão descritos na Tabela 5 a seguir.

Tabela 4: Deslocamentos verticais em vigas.

\begin{tabular}{|c|l|r|r|r|r|}
\hline & \multirow{2}{*}{ Seções } & \multicolumn{5}{|c|}{ Deslocamentos verticais (mm) } \\
\cline { 3 - 7 } Critérios & da viga & C30 & C35 & C40 & C60 \\
\hline Considerando & S1 & 8,8 & 8,4 & 8,2 & 7,9 \\
Variação da & S2 & 8,9 & 8,5 & 8,3 & 8 \\
área do pilar & S3 & 2,8 & 2,8 & 2,8 & 2,8 \\
\hline Sem & S1 & 8,8 & 8,1 & 7,6 & 6,5 \\
considerar & S2 & 8,9 & 8,2 & 7,7 & 6,5 \\
variação da & & & & & 2,6 \\
área do pilar & S3 & 2,8 & 2,6 & 2,4 & 2,1 \\
\hline
\end{tabular}

Fonte: Autor (2019).

A partir da Tabela 4, verificou-se que os deslocamentos verticais nas vigas apresentaram-se de maneira similar às flechas nas lajes, com deslocamento decrescente à medida que aumenta-se o fck e com a redistribuição dos esforços, devido alteração das áreas dos pilares, aumentando as flechas.

\section{IV.5 DESLOCAMENTOS HORIZONTAIS}

Para a verificação dos deslocamentos horizontais, aplicouse o parâmetro de instabilidade P-Delta do programa SAP2000 para uma combinação frequente de serviço (conforme NBR 6118 :2014) com o vento a $180^{\circ}$ e a $270^{\circ}$, por serem as faces Norte e Leste do prédio as de maior área de atuação destas cargas. Nestas condições, obtiveram-se os deslocamentos no topo do edifício, sendo os valores máximos em $\mathrm{Y}$ (vento a $270^{\circ}$ ) no pilar P1 e os valores máximo em X (em função do vento a $180^{\circ}$ ) no pilar P6, como se pode perceber nos mapas de deformações (Figuras 4 e 5 ) obtidos no SAP2000.

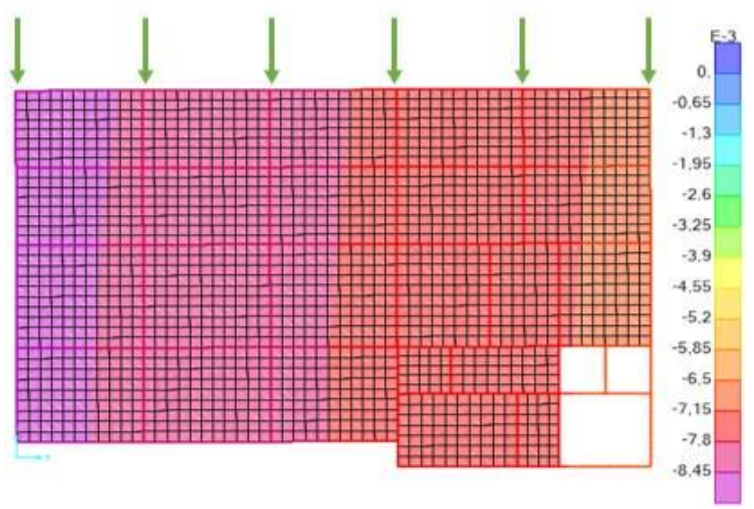

Figura5: Deslocamento em Y

Fonte: Autores, adaptado de SAP2000, (2019).
Os valores máximos para deslocamentos horizontais obtidos nos diferentes modelos estão listados na Tabela 5 abaixo, para os critérios com e sem mudança de área dos pilares.

Tabela 5: Deslocamentos Horizontais máximos.

\begin{tabular}{|c|c|c|c|c|}
\hline \multirow[b]{3}{*}{$\begin{array}{c}\text { Classe de } \\
\text { Resistência } \\
\text { do } \\
\text { Concreto }\end{array}$} & \multicolumn{4}{|c|}{ Deslocamentos máximos horizontais ( $\mathrm{mm}$ ) } \\
\hline & \multicolumn{2}{|c|}{$\mathrm{Em} Y$} & \multicolumn{2}{|c|}{$\mathrm{Em} X$} \\
\hline & $\begin{array}{c}\text { Sem } \\
\text { mudança } \\
\text { de área } \\
\text { do pilar }\end{array}$ & $\begin{array}{c}\text { Com } \\
\text { mudança } \\
\text { de área } \\
\text { do Pilar }\end{array}$ & \begin{tabular}{|c|} 
Sem \\
mudança \\
de área \\
do pilar
\end{tabular} & $\begin{array}{c}\text { Com } \\
\text { mudança } \\
\text { de área do } \\
\text { Pilar }\end{array}$ \\
\hline $\mathrm{C} 30$ & 8,7 & 8,7 & 1,8 & 1,8 \\
\hline C35 & 8,1 & 10,3 & 1,6 & 2 \\
\hline $\mathrm{C} 40$ & 7,5 & 8,4 & 1,5 & 1,6 \\
\hline $\mathrm{C} 60$ & 6,4 & 11 & 1,3 & 3,1 \\
\hline
\end{tabular}

Para a manutenção da mesma área nos demais modelos, observou-se resultado similar aos dos itens anteriores: as deformações diminuem, devido ao aumento do Módulo de Elasticidade, que é diretamente proporcional à resistência característica à compressão do concreto. Entretanto, quando se considera a diminuição da área do pilar devido à influência do fck na geometria das peças, tem-se um aumento dos deslocamentos horizontais, como já era esperado visto que os pilares tornaram-se mais esbeltos com o aumento da classe de resistência do concreto. Este resultado não pôde ser verificado nos deslocamentos do modelo com o fck $=40$, porque muitos dos seus pilares têm a mesma medida do modelo com $\mathrm{fck}=35$, como pode ser visto na planta de fôrma, e como visto quanto maior o fck, maior a rigidez.

\section{CONCLUSÃO}

Como era esperado, a modificação da resistência característica à compressão do concreto pode contribuir significativamente na determinação de propriedades dos materiais e da geometria da seção, dos deslocamentos verticais e horizontais e também das cargas finais dos pilares.

O Módulo de Elasticidade foi a propriedade do concreto mais notadamente influenciada pelo fck, como se pôde perceber quando se mantiveram as áreas da seção transversal dos pilares inalteradas entre os modelos de diferente fck. A adoção deste critério permitiu concluir que para uma mesma área, a consequência do efeito do fck no Módulo de Elasticidade se traduz na simples aplicação da Lei de Hooke, segundo a qual a deformação é inversamente proporcional ao Módulo de Elasticidade. Esta situação pôde ser verificada para os deslocamentos de todos os modelos que adotaram esse critério.

Além das propriedades do concreto, o fck influenciou de forma significativa as propriedades geométricas dos pilares, visto que foi fundamental na determinação das dimensões dos pilares pelo critério de dimensionamento aqui considerado. $\mathrm{O}$ uso de classes de resistência maiores do concreto implicou na redução das áreas dos pilares com influência significativa no carregamento dos pilares, na esbeltez dessas peças e, consequentemente, nos valores das deformações, os quais fizeram inferir uma relevante redistribuição dos esforços.

Visto que a mudança da área dos pilares nos diferentes modelos foi mais significativa na determinação de dados do que a simples mudança do fck mantendo a área de cada inalterada entre os modelos, conclui-se que a influência do fck nas verificações de análise estrutural se dá predominantemente através da mudança na rigidez final das peças estruturais. 


\section{AGRADECIMENTOS}

Agradecimento ao MSc. Eng. Daniel Veiga Adolfs, da AD Engenharia de Estruturas, pelos esclarecimentos sobre situações práticas de projetos de estruturas, que foram de grande importância para que os modelos estivessem mais próximos da realidade.

\section{REFERÊNCIAS}

[1] Mehta, P. K.; Monteiro, P. J. M., Concreto: Estrutura, Propriedades, Materiais. São Paulo, Pini, 1994.

[2] Pinheiro, Libânio M. Fundamentos do concreto e projeto de edifícios. 2007. Notas de aula. Universidade de São Paulo, São Carlos, 2007.

[3] Associação Brasileira de Normas Técnicas. NBR 8593: Concreto para fins estruturais - Classificação pela massa específica, por grupos de resistência e consistência. Rio de Janeiro: ABNT, 2015.

[4] Associação Brasileira de Normas Técnicas. NBR 6118: Projeto de estruturas de concreto - Procedimento. Rio de Janeiro: ABNT, 2014.

[5] Bernardo, João N.D.; Vargas, Alexandre. Análise da influência da resistência característica à compressão do concreto (fck) no dimensionamento estrutural de um edifício residencial em concreto armado. 2011. Trabalho de Conclusão de curso. Universidade do extremo Sul Catarinense, Criciúma, 2011.

[6] Martha, Luiz F. Análise de Estruturas: conceitos e métodos básicos. $2^{\mathrm{a}}$ Edição. Rio de Janeiro. Editora Elsevier, 2017.

[7] Bernincá, Matheus E. Comparação entre modelos de análise estrutural de edifícios em concreto armado: Estudo de caso. 2016. Trabalho de Conclusão de Curso. Universidade Federal do Rio Grande do Sul. Porto Alegre, 2016.

[8] Sussekind, José Carlos. Curso de Análise Estrutural - Volume 1. $4^{\mathrm{a}}$ Edição. Porto Alegre. Editora Globo, 1979.

[9] Hibbeler, Russel C. Resistência dos materiais; $7^{\text {a }}$ Edição. São Paulo. Editora Pearson Prentice Hall, 2010.

[10] Associação Brasileira de Normas Técnicas. NBR 6120: Cargas para o cálculo de estruturas de edificações. Rio de Janeiro: ABNT, 1980.

[11] Associação Brasileira de Normas Técnicas. NBR 6123: Força devidas ao vento em edificações. Rio de Janeiro: ABNT, 1988. 